\title{
Knowledge of and attitudes toward COVID-19 among parents of child dental patients during the outbreak
}

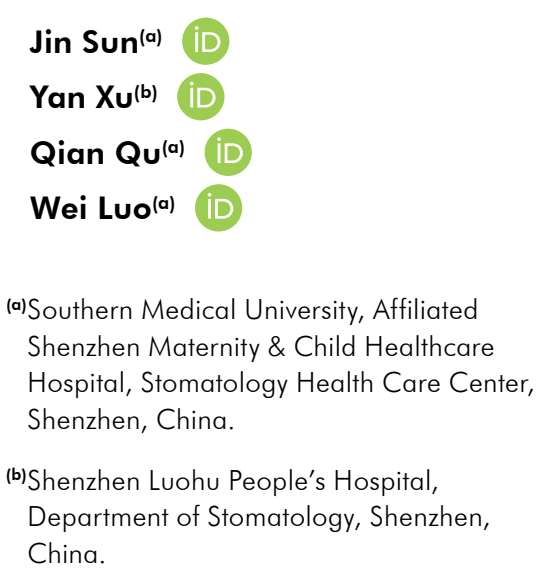

Declaration of Interests: The authors certify that they have no commercial or associative interest that represents a conflict of interest in connection with the manuscript.

\section{Corresponding Author:}

Jin Sun

E-mail:631589163@qq.com

hitps://doi.org/10.1590/1807-3107BOR-2020.vol34.0066

Submitted: March 21, 2020

Accepted for publication: April 29, 2020

Last revision: May 26, 2020

\begin{abstract}
The aim of this study was to evaluate the knowledge of and attitudes toward coronavirus disease 2019 (COVID-19) among the parents of child dental patients in Shenzhen during the outbreak. A structured questionnaire containing 10 questions was used, and each question had 2 or 3 possible answers. The parents of children (aged 0-14 years) who visited the dental department of our hospital last year were eligible to participate in this study. A total of 148 parents were interviewed by telephone in February 2020 by research staff. A total of $94.59 \%$ of the parents said they paid high attention to COVID-19 and explained it to their children; $66.22 \%$ thought the dental department environment was more dangerous than other public places; $91.89 \%$ believed the dental department had a higher risk of virus infection; and $83.78 \%$ said they would take their children to a dental department if the children had a severe toothache. Approximately $81.08 \%$ of the parents expressed confidence after we informed them about the preventive measures taken in the dental department to ensure safe treatment for their children. In conclusion, all parents were concerned about COVID-19, and most of them had talked about it with their children often. In addition, a considerable percentage of them would not take their children to the dental department even if they had severe dental pain and thought that the dental environment could be more dangerous than other environments. More information about this topic should be delivered to this population.
\end{abstract}

Keywords: Coronavirus Infections; COVID-19.

\section{Introduction}

During late 2019 and early 2020, a new fatal disease called coronavirus disease 2019 (COVID-19) broke out in China and Southeast Asia. It has been reported that COVID-19 appeared in Wuhan, Hubei Province, Central China, and then it was found in other places of China, Southeast Asia, Europe, North America, Oceania and almost all over the world, affecting more than 160 countries or districts. ${ }^{1,2}$ According to reports by the China CDC and authoritative organizations, by April 07, 2020, 1,393,797 people had been infected by COVID-19 globally.,3 The World Health Organization (WHO) announced that the COVID-19 outbreak had become a public health emergency of international concern on January 31, 2020, ${ }^{4}$ and then categorized it as a pandemic on March 11, 2020. ${ }^{5}$ 
The infectious agent of COVID-19 has been identified as a coronavirus called 2019-nCoV, which is similar to the 2003 SARS-CoV. The detection method confirmed that 2019-nCoV exists in saliva, bodily fluids, feces, and other samples from patients with COVID19. The virus spreads through close contact between people, especially through respiratory droplets. In addition, when people touch an object contaminated by infectious droplets and then touch their mouth, nose, or eyes, the virus can be transmitted. ${ }^{6}$ China has thus developed a high standard for measures aimed at preventing the spread of the virus. The most effective measures were social isolation to avoid rapid virus propagation, the protection of older people and patients with chronic diseases and low immunity and the implementation of health assistance to COVID19 patients via the rapid support of health workers from all over China.

Due to the nature of dental treatment, procedures typically produce aerosols and splatters, which can contain large amounts of saliva or blood from patients and thus carry the risk of large-scale transmission of the virus. ${ }^{7}$ Therefore, many health departments have asked dental departments to adopt strict measures. Such measures include screening patients, only providing emergency treatment, restricting aerosol operation as much as possible, using extensive protection, and performing environmental disinfection. However, researchers have reported that because some carriers have no symptoms, ${ }^{8}$ COVID-19 is difficult to control in the dental environment. Many patients have received COVID-19-related information through hospital propaganda and education.

During the COVID-19 outbreak, people have received a large volume of information that could lead to confusion, for example, contamination risks during dental appointments from announcements of administrative districts and dentist associations. It is important to know if there are any misconceptions, so that dental professionals can help improve hospital measures as well as patient education. Thus, the present study aimed to evaluate the knowledge of and attitudes toward COVID-19 among the parents of child dental patients in Shenzhen during the outbreak in February 2020.

\section{Methodology}

\section{Research interviewees}

In February 2020, the researchers interviewed parents by telephone in a randomized manner. The parents' children (aged 0-14 years) visited the dental department of our hospital last year. Researchers made 156 calls; among them, 148 calls of parents were obtained as connections, while others were not. The researchers first explained the purpose of the study and obtained the parents' consent. To ensure privacy and confidentiality, individual results will not be publicly displayed or provided to other individuals or organizations in any form. All data obtained are not for commercial profit. Follow-up treatment will not be provided differently due to specific data. With the consent of all authors, the questions and forms of investigation were considered ethical.

\section{Questionnaire}

The questionnaire contained 10 questions and was based on similar research. ${ }^{9}$ Because the parents were Chinese, the questions were written in Chinese. The translated questionnaire is given below.

1. Your gender (male or female).

2. Your age $(20-29,30-39,40-49$, over 50$)$.

3. 3. Do you pay attention to COVID-19 (always, occasionally, never)?

4. Do you explain COVID-19 to your child/ children (often, occasionally, never)?

5. Do you think the environment of the dental department is more dangerous than that of other public places (yes, similar, no)?

6. Do you think dental treatment could cause your child/children to become infected by the virus (yes, similar to the risk in other places, no)?

7. How might your child/children be infected by the virus during dental treatment (droplets, blood, medical apparatus/instruments, the dentists themselves)? (Note: patients could select one or more of these options)

8. If your child/children had a toothache, would you take him/her/them to the dental department (yes if in severe pain or absolutely not)?

9. The dental department has taken various protective measures according to the 
requirements of the health committee, including patient screening, hospital environment disinfection, and special protective equipment for both dentists and patients. Will these measures give you confidence in dental treatment (yes or no)?

10. What is your highest level of education completed (junior college, undergraduate, postgraduate)?

\section{Statistical analysis}

Each option was converted to 1 and 2 or 1, 2, and 3 points. Excel (Microsoft, USA) and GraphPad Prism (GraphPad Software Inc., USA) were used for statistical analysis. One-way analysis tests with Bonferroni adjustment for multiple comparisons were used to compare pooled questionnaire responses by age group, education level, and gender. A p-value of less than 0.05 was considered to be statistically significant.

\section{Results}

The basic data on gender, age, highest level of education, and the other 7 questions, as well as the percentages of answers, are shown in Table 1.

All parents were concerned about COVID-19, and almost all of them were always concerned. Among the parents, all had explained COVID19 to their child/children. The ratio among parents aged $40-49$ years and 50 years or above who explained it to their children was often significantly higher, while the ratio among those aged 30-39 years was significantly lower. Meanwhile, the ratio among parents with a junior college education who explained it often was significantly higher than the ratio among parents with an undergraduate or a graduate education. No significant differences were observed by parent gender (Tables 1 and 2).

Table 1. Questions and percentage of answers recorded overall.

\begin{tabular}{|c|c|c|c|c|}
\hline \multirow{3}{*}{$\begin{array}{l}\text { Questions } \\
\text { 1. Your gender }\end{array}$} & \multicolumn{4}{|c|}{ Answers and percentages (number/ratio) } \\
\hline & Male & Female & & \\
\hline & $64(43.24 \%)$ & $84(56.76 \%)$ & & \\
\hline \multirow{2}{*}{ 2. Your age } & 20-29 & 30-39 & $40-49$ & Over 50 \\
\hline & $22(14.86 \%)$ & $96(64.86 \%)$ & $16(10.81 \%)$ & $14(9.46 \%)$ \\
\hline \multirow{2}{*}{ 3. Do you pay attention to COVID-19? } & Always & Occasionally & Never & \\
\hline & $140(94.59 \%)$ & $8(5.41 \%)$ & 0 & \\
\hline \multirow{2}{*}{ 4. Do you explain COVID-19 to your child/children? } & Always & Occasionally & Never & \\
\hline & $68(45.95 \%)$ & 80 (54.05\%) & 0 & \\
\hline \multirow{2}{*}{$\begin{array}{l}\text { 5. Do you think the environment of the dental department is more } \\
\text { dangerous than that of other public places? }\end{array}$} & Yes & Similar & No & \\
\hline & 98 (66.22\%) & 46 (31.08\%) & $4(2.7 \%)$ & \\
\hline \multirow[t]{2}{*}{$\begin{array}{l}\text { 6. Do you think the dental treatment could cause your child/children to } \\
\text { become infected by the virus? }\end{array}$} & Yes & $\begin{array}{l}\text { Similar to the } \\
\text { risk in other } \\
\text { places }\end{array}$ & No & \\
\hline & $136(91.89 \%)$ & $8(5.41 \%)$ & $4(2.7 \%)$ & \\
\hline \multirow[t]{2}{*}{$\begin{array}{l}\text { 7. How might your child/children be infected by the virus during dental } \\
\text { treatment? (one or more choices) }\end{array}$} & Droplets & Blood & $\begin{array}{l}\text { Medical } \\
\text { apparatus/ } \\
\text { instruments }\end{array}$ & $\begin{array}{l}\text { The dentists } \\
\text { themselves }\end{array}$ \\
\hline & 142 (95.95\%) & $108(72.97 \%)$ & 98 (66.22\%) & 102 (68.92\%) \\
\hline \multirow{2}{*}{$\begin{array}{l}\text { 8. If your child/children had a toothache, would you take him/her/them } \\
\text { to the dental department? }\end{array}$} & $\begin{array}{c}\text { Yes, if in severe } \\
\text { pain }\end{array}$ & Absolutely not & & \\
\hline & $124(83.78 \%)$ & $24(16.22 \%)$ & & \\
\hline $\begin{array}{l}\text { 9. The dental department has taken various protective measures } \\
\text { according to the requirements of the health committee, including } \\
\text { patient screening, hospital environment disinfection, and the provision } \\
\text { of special protective equipment for both dentists and patients. Will these } \\
\text { measures give you confidence in dental treatment? }\end{array}$ & 120 (81.08\%) & 28 (18.92\%) & & \\
\hline 10. What is your highest level of education completed? & $\begin{array}{l}\text { Junior college } \\
20(13.51 \%)\end{array}$ & $\begin{array}{l}\text { Undergraduate } \\
92(62.16 \%)\end{array}$ & $\begin{array}{l}\text { Postgraduate } \\
36(24.32 \%)\end{array}$ & \\
\hline
\end{tabular}


More than two-thirds of parents thought that the environment of the dental department was more dangerous than that of other public places, while others thought it was similar or not dangerous. Among them, the ratio among parents aged 40-49 years who thought the dental department environment was more dangerous was significantly higher than that among parents aged 20-29. Meanwhile, the ratio among parents with a junior college education was higher, while the ratio among parents with undergraduate and postgraduate education was relatively lower. Parents in different gender groups showed no significant differences (Tables 1 and 3).

Most parents thought that their children could be easily infected with the virus while receiving dental treatment; few thought that the risk was similar to that of other public places or that there was no significant risk. Among them, most thought that droplet blood was the main cause of infection, while more than half of them thought it might be a medical apparatus

Table 2. Data on parents explaining COVID-19 to their child/children (by parent age, level of education and gender).

\begin{tabular}{|c|c|c|c|c|}
\hline \multicolumn{5}{|c|}{ Explaining COVID-19 to child/children (number/ratio) } \\
\hline Variable & Always & Occasionally & Never & $\mathrm{p}$-value \\
\hline \multicolumn{5}{|l|}{ Age (year) } \\
\hline $20-29$ & $12(54.55 \%)$ & $10(45.45 \%)$ & 0 & \\
\hline $30-39$ & $32(33.33 \%)$ & $64(63.67 \%)$ & 0 & $p=0.0012, p<0.0001$ \\
\hline $40-49$ & $12(75 \%)$ & $4(25 \%)$ & 0 & $p=0.0012$ \\
\hline$\geq 50$ & $12(85.71 \%)$ & $2(14.29 \%)$ & 0 & $p<0.0001$ \\
\hline \multicolumn{5}{|l|}{ Level of education } \\
\hline Junior college education & $18(90 \%)$ & $2(10 \%)$ & 0 & $p=0.0056, p<0.0001$ \\
\hline Undergraduate education & $36(39.13 \%)$ & $56(60.87 \%)$ & 0 & $p=0.0056$ \\
\hline Graduate education & $14(38.89 \%)$ & $22(61.11 \%)$ & 0 & $p<0.0001$ \\
\hline \multicolumn{5}{|l|}{ Parent gender } \\
\hline Male & 32 (50\%) & 32 (50\%) & 0 & \\
\hline Female & $36(42.86 \%)$ & 48 (57.14\%) & 0 & \\
\hline
\end{tabular}

Table 3. Data on beliefs that the environment of the dental department was more dangerous than that of other public places (by parent age, level of education and gender).

Thought that the environment of the dental department was more dangerous than that of other public places (number/ratio)

\begin{tabular}{|c|c|c|c|c|}
\hline Variable & Yes & Similar & No & $p$-value \\
\hline \multicolumn{5}{|l|}{ Age (year) } \\
\hline 20-29 & $8(36.36 \%)$ & $14(63.64 \%)$ & 0 & $p<0.001$ \\
\hline $30-39$ & $64(66.67 \%)$ & $28(29.17 \%)$ & $4(4.17 \%)$ & \\
\hline $40-49$ & $16(100 \%)$ & 0 & 0 & \\
\hline$\geq 50$ & 10 (71.43\%) & $4(28.57 \%)$ & 0 & $p<0.001$ \\
\hline \multicolumn{5}{|l|}{ Level of education } \\
\hline Junior college education & $18(90 \%)$ & $2(10 \%)$ & 0 & $p=0.016$ \\
\hline Undergraduate education & 54 (58.79\%) & $34(36.86 \%)$ & $4(4.35 \%)$ & $p=0.016$ \\
\hline Graduate education & $26(72.22 \%)$ & $10(27.78 \% 0$ & 0 & \\
\hline \multicolumn{5}{|l|}{ Parent gender } \\
\hline Male & $48(75 \%)$ & 14 (21.88\%\%) & $2(3.12 \%)$ & \\
\hline Female & $50(59.52 \%)$ & $32(38.1 \%)$ & $2(2.38 \%)$ & \\
\hline
\end{tabular}


or the dentists themselves. The ratio among parents aged 40-49 years and 50 years or above who thought their children could be easily infected during dental treatment was higher, while the ratio among those aged 20-29 years was relatively lower. Meanwhile, parents in different education and gender groups showed no significant differences (Tables 1 and 4).

More than half of the parents would take their child to the dentist during the outbreak if he/she had a severe toothache; the rest would absolutely not. Among them, compared to the parents aged 40-49 years, parents aged 20-29 were more willing to take their children to a dental department for toothache treatment. Meanwhile, parents with a junior college education were less willing, while those with a postgraduate education were relatively more willing. There were no significant differences in this regard between male and female parents (Tables 1 and 5).

Most parents expressed confidence in the dental department after learning that the department had taken protective measures; the rest were still not confident. Compared to parents aged $40-49$ years, the ratio among those aged 20-29 years and 50 years or above was relatively higher. There were no significant differences among parents in different education groups and gender groups (Tables 1 and 6).

Table 4. Data on parents' beliefs that their children could be easily infected during dental treatment (by parent age, level of education and gender).

\begin{tabular}{lccc}
\hline \multicolumn{4}{c}{ Thought that their children could be easily infected during dental treatment (number/ratio) } \\
\hline Variable & Yes & Similar & No \\
\hline Age (year) & $18(81.82 \%)$ & $2(9.09 \%)$ & $2(9.09 \%)$ \\
$20-29$ & $88(91.67 \%)$ & $6(6.25 \%)$ & $2(2.08 \%)$ \\
$30-39$ & $16(100 \%)$ & 0 & 0 \\
$40-49$ & $14(100 \%)$ & 0 & 0 \\
$\geq 50$ & & $2(10 \%)$ & 0 \\
Level of education & $18(90 \%)$ & 0 & $4(4.17 \%)$ \\
Junior college education & $88(91.67 \%)$ & $6(16.67 \%)$ & 0 \\
Undergraduate education & $30(83.33 \%)$ & $2(3.13 \%)$ & $2(3.13 \%)$ \\
$\quad$ Graduate education & $60(93.75 \%)$ & $6(7.14 \%)$ & $2(2.38 \%)$ \\
Parent gender & $76(90.48 \%)$ & \\
Male & & & \\
Female & & & \\
\hline
\end{tabular}

Table 5. Data on parents' willingness to take their children to a dental department for toothache treatment (by parent age, level of education and gender).

\begin{tabular}{|c|c|c|}
\hline \multicolumn{3}{|c|}{$\begin{array}{l}\text { Willing to take their children to a dental department for toothache } \\
\text { treatment (number/ratio) }\end{array}$} \\
\hline Variable & $\begin{array}{l}\text { Yes, if in severe } \\
\text { pain }\end{array}$ & Absolutely not \\
\hline \multicolumn{3}{|l|}{ Age (years) } \\
\hline $20-29$ & 20 (90.91\%) & 2 (9.09\%) \\
\hline 30-39 & 80 (83.33\%) & $16(16.67 \%)$ \\
\hline $40-49$ & $12(75 \%)$ & $4(25 \%)$ \\
\hline$\geq 50$ & 12 (85.71\%) & $2(14.29 \%)$ \\
\hline \multicolumn{3}{|l|}{ Level of education } \\
\hline Junior college education & $16(80 \%)$ & $4(20 \%)$ \\
\hline Undergraduate education & $76(82.61 \%)$ & $16(17.39 \%)$ \\
\hline Graduate education & 32 (88.89\%) & $4(11.11 \%)$ \\
\hline \multicolumn{3}{|l|}{ Parent gender } \\
\hline Male & $56(87.5 \%)$ & 8 (12.5\%) \\
\hline Female & 68 (80.95\%) & 16 (19.05\%) \\
\hline
\end{tabular}

Table 6. Data on parents' confidence in the dental department after learning that the department had taken protective measures (by parent age, level of education and gender).

\begin{tabular}{|c|c|c|}
\hline \multicolumn{3}{|c|}{$\begin{array}{l}\text { Expressing confidence in the dental department after learning that } \\
\text { the department had taken protective measures (number/ratio) }\end{array}$} \\
\hline Variable & Yes & No \\
\hline \multicolumn{3}{|l|}{ Age (years) } \\
\hline $20-29$ & 20 (90.91\%) & $2(9.09 \%)$ \\
\hline $30-39$ & $76(79.17 \%)$ & $20(20.83 \%)$ \\
\hline $40-49$ & 10 (62.5\%) & $6(37.5 \%)$ \\
\hline$\geq 50$ & $14(100 \%)$ & 0 \\
\hline \multicolumn{3}{|l|}{ Level of education } \\
\hline Junior college education & $14(70 \%)$ & $6(30 \%)$ \\
\hline Undergraduate education & $78(84.78 \%)$ & $14(15.22 \%)$ \\
\hline Graduate education & $28(77.78 \%)$ & $8(22.22 \%)$ \\
\hline \multicolumn{3}{|l|}{ Parent gender } \\
\hline Male & $50(78.13 \%)$ & $14(21.87 \%)$ \\
\hline Female & $70(83.33 \%)$ & $14(16.67 \%)$ \\
\hline
\end{tabular}




\section{Discussion}

Parents are a special group. Even though children are the main subjects of many medical or educational activities, the behavior of the parents is almost equally important. Parents act as the primary implementers or supervisors of children's daily oral care.

\section{Knowledge}

Today, people can access news in various ways thanks to the work of the Chinese administration, the timely reporting of official media, and the transparency and timeliness of modern multimedia platforms. It is a good sign that all parents we interviewed expressed concern about COVID-19. A previous survey conducted in Hong Kong during the 2003 SARS outbreak found that approximately $80 \%$ of the respondents paid attention to SARS via regularly watching or listening to the news. ${ }^{9}$ Since modern multimedia spreads more easily and more widely, people can receive much information on COVID-19. This means that modern multimedia has played an important role in this outbreak. Among the respondents in our survey, all of them passed on COVID-19 information to their children, indicating that they highly value their children's health. However, parents aged 30-39 years spent less time talking to their children about COVID-19. We may speculate that parents in this age group are in a busy period of life and work and thus spend less time caring for their children. Parents and medical workers should seek to improve this situation. In addition, parents with undergraduate and postgraduate degrees were also less likely to talk to their children always about COVID; we speculate that the same reason mentioned above applies.

The cause of COVID-19 is a coronavirus similar to the SARS virus of $2003 .^{10}$ The virus can be spread through saliva, bodily fluids, feces, and airborne droplets when people cough or sneeze, which is the major route of transmission. ${ }^{11,12}$ Since dental treatment can involve considerable saliva or blood splatter from the patient, it can carry a high risk of virus transmission. ${ }^{13,14}$ Therefore, the dental department has a higher risk of infection than other departments or other places. Accordingly, $66.22 \%$ of the parents thought the dental department was more dangerous than other places. However, not all parents were able to understand the particularities of the dental department. Among them, the ratio among parents aged 20-29 with undergraduate and postgraduate education was relatively lower. We think that the percentage was not high enough. We believe this finding is attributable to insufficient awareness and education on the part of the relevant health authorities. Through investigation, we found that such information is often an internal requirement of public health authorities for hospitals and departments, and some hospitals post it on their own multimedia network or the departments' notice boards. However, few people have access to such information due to a lack of public media channels, such as news and community announcements. This is the area that health authorities should seek to improve. Fortunately, most dental departments and dental clinics in our city have done their best to provide professional explanations and suggestions for patients, both online and on-site, and have effectively reduced the number of nonemergency patients. In other words, hospitals and doctors have done their part to prevent the spread of the virus.

A total of $91.89 \%$ of the parents agreed that their child/children could be easily infected with the virus while receiving dental treatment. Among them, the ratio among parents aged $40-49$ years and 50 years or above was significantly higher. Further investigation reveals that most parents can correctly understand the source of the virus infection as droplets and blood. However, more than half of them thought it may be a medical apparatus as well as dentists themselves. This indicates that parents have poor trust in the protection measures of the hospital, and they are wrong to worry about the sterilization and disinfection of our medical apparatus, as well as the respective protection measures between dentists and patients. This enlightens us that we need to strengthen the propaganda of hospital protection work during the outbreak of COVID-19 to let parents know that we can minimize the droplets and blood or aerosols produced in the treatment process and adequately disinfect and sterilize our medical equipment, as well as perfect protective measures between dentists and patients. 


\section{Attitudes}

We made assumptions over the phone; $82.49 \%$ of the parents said that they would take their child/ children to the hospital for treatment during the COVID-19 outbreak if the child/children had a severe toothache, while the rest said that they would not. We believe that this practice of these approximately $20 \%$ parents would prolong their child's/children's condition, which may lead to a greater incidence of dental disease. Thus, we then informed them about preventive measures undertaken by municipal health departments, dental associations and dental departments, which include patient screening (COVID19 or suspected patients visiting), the strengthening of hospital environment disinfection, and the provision of special protective equipment for both dentists and patients (using gargles, rubber dams, strong suction and other equipment). ${ }^{15,16}$ Previous studies have confirmed that the preventive measures above are effective against the virus., ${ }^{7,1718}$ Approximately $81.08 \%$ of the parents expressed confidence after we informed them about preventive measures. Among the parents who absolutely did not want to take their child/children to the hospital for treatment, 50\% of them began to feel relieved. This indicates that the parents have high confidence in the prevention and control policies undertaken by the government and hospitals. In a survey conducted in Hong Kong during the 2003 SARS outbreak, over two-thirds of respondents from different age groups (68.7\%), different genders $(68.6 \%)$, and different education levels $(68.8 \%)$ said they were not worried about contracting SARS in the dental setting and did not want to avoid dental treatment. ${ }^{9}$ The present study's findings are similar. This indicates that the medical quality of our city's dental departments is comparable to that of developed regions, which is a good sign.

A good treatment program during specific periods is not a formalized, fully open office or an overly cautious shutdown; rather, it should be conducted based on the actual situation under professional infection control measures. Since the outbreak of COVID-19 in China in January 2020, local health departments have issued documents requiring dental staff to optimize procedures for diagnosis and treatment according to medical regulations. All operations have been performed strictly following these procedures, and thus far, no cases of cross-infection have been reported in the dental setting. Nevertheless, parents need to have a correct understanding of dental procedures and should try to avoid taking their children to hospitals or dental clinics if it is not urgent. In cases of emergency, however, timely medical treatment should be sought, and the appropriate precautions should be observed.

In this study, the 148 parents were relatively onesided and did not fully reflect the knowledge and attitudes of all parents. However, this study occurred during the outbreak of COVID-19, coupled with a lack of dental staff and the limitations of treatment projects. At the same time, we should consider the timeliness of parents' thinking, that is, to avoid causing parents fatigue and hassle due to outbreakrelated delays in treatment. Therefore, this study represents a temporarily small sample, which we think has certain research significance.

\section{Conclusion}

Although all parents were concerned about COVID19 , and most of them had talked about it with their children often, a considerable percentage of them would not take their children to the dental department even if their children had severe dental pain and thought that the dental environment could be more dangerous than other environments. More effort should be directed toward informing the public that some measures can be taken to avoid contamination in dental offices and that urgent cases can be treated with lower risk.

\section{Acknowledgments}

We thank LetPub and American Journal Experts company for its linguistic assistance during the preparation of this manuscript in the outbreak of COVID-19. 


\section{References}

1. Zhu N, Zhang D, Wang W, Li X, Yang B, Song J, et al. A novel coronavirus from patients with pneumonia in China, 2019. N Engl J Med. 2020 Feb;382(8):727-33. https://doi.org/10.1056/NEJMoa2001017

2. DXY - DX Doctor. COVID-19 global pandemic real-time report. [cited 2020 Apr 7]. Available from: https://ncov.dxy.cn/ncovh5/view/ en_pneumonia?from $=d x y \&$ source $=\&$ link $=\&$ share $=$

3. People's Republic of China. National Health Commission. Novel coronavirus pneumonia epidemic situation up to April $724: 00$ [cited 2020 Apr 8]. Available from: http://www.nhc.gov.cn/yjb/s7860/202004/5e2b6f0bd47d48559582242e3878447d.shtml

4. People's Republic of China. National Health Commission. WHO announced novel coronavirus infection pneumonia had become "a public health emergency" of international concern: travel and trade restrictions on China are not recommended.. [cited 2020 Jan 31 ]. Available from: http://www.nhc.gov.cn/xcs/yqfkdt/202001/b196e4f678bc4447a0e4440f92dac81b.shtml

5. World Health Organization - WHO. WHO Director-General's opening remarks at the media briefing on COVID-19. [cited 2020 Mar 11]. Available from: https://www.who.int/dg/speeches/detail/who-director-general-s-opening-remarks-at-the-media-briefing-on-covid19---11-march-2020

6. Holshue ML, DeBolt C, Lindquist S, et al. First case of 2019 Novel Coronavirus in the United States. N Engl J Med. 2020 Mar 5;382(10):929-936. https://doi.org/10.1056/NEJMoa2001191

7. Harrel SK, Molinari J. Aerosols and splatter in dentistry: a brief review of the literature and infection control implications. J Am Dent Assoc. 2004 Apr;135(4):429-37. https://doi.org/10.14219/jada.archive.2004.0207

8. Huang C, Wang Y, Li X, Ren L, Zhao J, Hu Y, et al. Clinical features of patients infected with 2019 novel coronavirus in Wuhan, China. Lancet. 2020 Feb;395(10223):497-506. https://doi.org/10.1016/S0140-6736(20)30183-5

9. Yip HK, Tsang PC, Samaranayake LP, Li AH. Knowledge of and attitudes toward severe acute respiratory syndrome among a cohort of dental patients in Hong Kong following a major local outbreak. Community Dent Health. 2007 Mar;24(1):43-8.

10. Wu F, Zhao S, Yu B, Chen YM, Wang W, Song ZG, et al. A new coronavirus associated with human respiratory disease in China. Nature. 2020,03;579(7798):265-269. https://doi.org/10.1038/s41586-020-2008-3

11. Lu CW, Liu XF, Jia ZF. -nCoV transmission through the ocular surface must not be ignored. Lancet. 2020 Feb;395(10224):e39. https://doi.org/10.1016/S0140-6736(20)30313-5

12. Belser JA, Rota PA, Tumpey TM. Ocular tropism of respiratory viruses. Microbiol Mol Biol Rev. 2013 Mar;77(1):14456. https://doi.org/10.1128/MMBR.00058-12

13. Kampf G, Todt D, Pfaender S, Steinmann E. Persistence of coronaviruses on inanimate surfaces and their inactivation with biocidal agents. J Hosp Infect. 2020 Mar;104(3):246-51. https://doi.org/10.1016/j.jhin.2020.01.022

14. Chen J. Pathogenicity and transmissibility of 2019-nCoV-a quick overview and comparison with other emerging viruses. Microb Infect; 2020 Mar;22(2):69-71. https://doi.org/10.1016/i.micinf.2020.01.004

15. Zhang WJ, Jiang XQ. Measures and suggestions for the prevention and control of the novel coronavirus in dental institutions. Front Oral Maxillofac Med. 2020;2:4. https://doi.org/10.21037/fomm.2020.02.01

16. Peng X, Xu X, Li Y, Cheng L, Zhou X, Ren B. Transmission routes of 2019-nCoV and controls in dental practice. Int J Oral Sci. 2020 Mar;12(1):9. https://doi.org/10.1038/s41368-020-0075-9

17. Smales FC, Samaranyake LP. Maintaining dental education and specialist dental care during an outbreak of a new coronavirus infection. Part 1: a deadly viral epidemic begins. Br Dent J. 2003 Nov;195(10):557-61. https://doi.org/10.1038/sj.bdj.4810723

18. Wiley L. The Government of the Hong Kong Special Administrative Region Department of Health. 2020 [cited 2020 Jan 28]. Available from: https://www.chp.gov.hk/en/index.html 